\title{
Fighting Poor Quality Medicines: Development, Transfer and Validation of Generic HPLC Methods for Analyzing Two WHO Recommended Antimalarial Tablets
}

\author{
Jérémie Kindenge Mbinze ${ }^{1,2^{*}}$, Achille Yemoa ${ }^{1,3^{*}}$, Pierre Lebrun1, Pierre-Yves Sacré1, \\ Védaste Habyalimana ${ }^{1,4}$, Nicodème Kalenda1,2, André Bigot ${ }^{3}$, Eugène Atindehou ${ }^{5}$, \\ Philippe Hubert ${ }^{1}$, Roland Djang'eing'a Marini' ${ }^{1 \#}$
}

\footnotetext{
${ }^{1}$ University of Liege (ULg), Department of Pharmacy, CIRM, Laboratory of Analytical Chemistry, Liège, Belgium ${ }^{2}$ Laboratoire d'Analyse des Médicaments, Département de Galénique et d'Analyse des Médicaments, Université de Kinshasa, Kinshasa XI, Democratic Republic of Congo

${ }^{3}$ UFR Pharmacie, Faculté des Sciences de Santé, Université d'Abomey Calavi, Cotonou, Bénin

${ }^{4}$ Rwanda Biomedical Center, Medical Procurement and Production Division, Butare, Rwanda

${ }^{5}$ Université Félix Houphouet Boigny, Abidjan, Côte d'Ivoire

Email: ${ }^{\text {rmarini@ulg.ac.be }}$
}

Received 26 December 2014; accepted 15 January 2015; published 20 January 2015

Copyright (C) 2015 by authors and Scientific Research Publishing Inc.

This work is licensed under the Creative Commons Attribution International License (CC BY).

http://creativecommons.org/licenses/by/4.0/

(c) (i) Open Access

\section{Abstract}

As serious but neglected public health problems, poor quality medicines, i.e. for antimalarial medicines, urged to be fought. One of the approaches is to consider the analytical chemistry and separative techniques. In this study, a generic liquid chromatographic method was firstly developed for the purpose of screening 8 antimalarial active ingredients, namely amodiaquine (AQ), piperaquine (PPQ), sulfalene (SL), pyrimethamine (PM), lumefantrine (LF), artesunate (AS), artemether (AM) and dihydroartemisinine (DHA) by applying DoE/DS optimization strategy. Since the method was not totally satisfying in terms of peak separation, further experiments were undergone applying the same development strategy while splitting the 8 ingredients into five groups. Excellent prediction was observed prior to correlation between retention times of predicted and observed separation conditions. Then, a successful geometric transfer was realized to reduce the analysis time focusing on the simultaneous quantification of two WHO's recommended ACTs in anti-malarial fixed-dose combination (AM-LF and AS-AQ) in tablets. The optimal separation was achieved using an isocratic elution of methanol-ammonium formate buffer $(\mathrm{pH} 2.8 ; 10 \mathrm{mM})(82.5: 17.5, \mathrm{v} / \mathrm{v})$

\footnotetext{
*These authors have equally contributed to this article.

\#Corresponding author.
}

How to cite this paper: Mbinze, J.K., et al. (2015) Fighting Poor Quality Medicines: Development, Transfer and Validation of Generic HPLC Methods for Analyzing Two WHO Recommended Antimalarial Tablets. American Journal of Analytical Chemistry, 6, 127-144. http://dx.doi.org/10.4236/ajac.2015.62012 
at $0.6 \mathrm{ml} / \mathrm{min}$ through a $\mathrm{C} 18$ column $(100 \mathrm{~mm} \times 3.5 \mathrm{~mm}, 3.5 \mu \mathrm{m})$ thermostated at $25^{\circ} \mathrm{C}$. After a successful validation stage based on the total error approach, the method was applied to determine the content of AM/LF or AS/AQ in seven brands of antimalarial tablets currently marketed in West, Central and East Africa. Satisfying results were obtained compared to the claimed contents.

\section{Keywords}

\section{Antimalarial, ACT, Simultaneous Determination, Poor Quality Substances, Design of Experiments, Design Space, Method Transfer, Accuracy Profile}

\section{Introduction}

Poor quality medicines are serious but neglected public health problems. Anti-infective medicines are particularly afflicted [1]. Poor-quality antimalarials that contain sub-therapeutic amounts of active ingredient increase the risk of malaria drug resistance, thus undoing the significant gains in malaria control seen in the last decade [2]. In 2012, WHO estimated 207 million malaria cases worldwide [2]. The successful control of this disease depends mainly on treatment with efficacious anti-malarial drugs. Most of the countries do have a National Malaria Treatment Policy that specifies medicines for treatment of both uncomplicated and severe malaria as well as malaria in case of pregnancy and in case of first line treatment fails. As resistance develops to known medicines, it is necessary to commercialize new ones or to use the existing medicines in combination for example in case of malaria infection with Plasmodium falciparum. Indeed, the use of two or more drugs with different action mechanism is now recommended to provide adequate cure rate and delay any development of resistance [3]. WHO recommends that all persons of all ages in all epidemiological settings with suspected malaria should receive a parasitological confirmation of diagnosis by either microscopy or rapid diagnostic test (RDT), and that uncomplicated Plasmodium falciparum malaria should be treated with an artemisinin-based combination therapy (ACT) [2].

Fast acting artemisinin-based compounds are combined with a drug from a different class. Companion drugs include lumefantrine, mefloquine, amodiaquine, sulfadoxine/pyrimethamine, piperaquine and chlorproguanil/ dapsone. The artemisinin derivatives usually used including dihydroartemisinin, artesunate and artemether. Implementation of the recommendation to use ACTs is limited by the small number of available and affordable coformulated anti-malarial drugs, but most countries are now starting to implement this regimen. A co-formulated drug is one in which two different drugs are combined in one tablet; this is important to ensure both drugs are used.

Artemether/lumefantrine was the first fixed-dose artemisinin-based combination therapy recommended and pre-qualified by WHO for the treatment of uncomplicated malaria caused by P. falciparum. It has been shown to be effective both in sub-Saharan Africa and in areas with multi-drug resistant $P$. falciparum in Southeast Asia. It is currently recommended as first-line treatment for uncomplicated malaria in several countries. However, its complex treatment regimen of two doses daily for three days could affect patient adherence to treatment. A fixeddose combination of amodiaquine-artesunate was launched in February 2007 [3]. The benefits of ACTs are their high efficacy, fast action and the reduced likelihood of resistance developing. In order to make best use of them, it is critical to address issues of quality.

According to WHO 200,000 deaths over one million that occur from malaria annually would be avoidable if the available medicines were effective, of good quality and used correctly [4]. A recent study published in "The Lancet" concluded that up to $40 \%$ of artesunate products (the best medicine to combat resistant malaria today) contain no active ingredients and therefore have no therapeutic benefits. At best, the regular use of substandard or counterfeit medicines leads to therapeutic failure or drug resistance; in many cases it can lead to death [4].

In this context, analytical chemistry and especially separative screening methods such as liquid chromatography (LC) methods are suitable to help fighting against such medicines and therefore can be used [5]-[7].

Recently, Debrus et al. published interesting work on an innovative HPLC method development for the screening of 19 antimalarial drugs based on a generic approach, using design of experiments, independent component analysis and design space. That method was found somewhat time consuming due to the gradient mode [8]. 
In the present study, several HPLC separations considering isocratic mode (short run time) were optimized for targeted subsets of 8 antimalarial active ingredients (AAI) used alone or in combination.

The first objective was the optimization of the separation conditions (screening method) for these 8 AAI among which were 4 companion drugs (amodiaquine (AQ), piperaquine (PPQ), sulfalene (SL), pyrimethamine (PM) lumefantrine (LF)) and Artemisinin derivatives include dihydroartemisinin (DHA), artesunate (AS) and artemether (AM). Their chemical structures are presented in Figure 1.

The second objective was the simultaneous determination of artemether, lumefantrine, artesunate, amodiaquine in fixed dose combination tablets as recommended by WHO. As suggested in ICH Q8 (R2) and previously successfully tested by Debrus et al. [8] [9], a combining design of experiments (DoE) and Design Space (DS) was exploited to simultaneously optimize the separation based on predictive modeling technique using retention time-based responses [10]. Thereafter, a geometric transfer was performed for the HPLC developed methods in order to evaluate the robustness and improved gain of analysis time that is a challenge in the framework of fighting against counterfeit medicines.

The third objective was to validate the transferred method using the accuracy profile as decision tool for the simultaneous quantitation of artemether and lumefantrine; artesunate and amodiaquine in fixed dose combination (FDC) tablets.

Finally, the validated method was used to analyze several antimalarial drugs marketed in Benin (West Africa), DRC (Central Africa) and Rwanda (East Africa).

\section{Experimental}

\subsection{Chemical and Reagents}

Methanol (HPLC gradient grade), formic acid (98\% - 100\%) and orthophosphoric acid Eur Ph. grade (85\%) were purchased from Merck (Darmstadt, Germany). Ammonium formate (99\%) was provided by BDH Prolabo (Almere, Netherlands). Ultrapure water was obtained from a Milli-Q Plus 185 water purification system from Millipore (Billerica, MA, USA). Artesunate (99.8\%) and dihydroartemisinin alpha and beta (100.0\%) were purchased from Apoteket AB (Stockholm, Sweden). Lumefantrine (99.4\%) and artemether (99.5\%) were kindly donated by Fourrts laboratories (Chennai, India) and Meridian Pharmacare Pvt Ltd. (Bangalore, Inde). Amodiaquine hydrochloride (99.0\%), Piperaquine tetraphosphate (99.2\%) and Pyrimethamine (99.0\%) were purchased from Sigma Aldrich (St. Louis, MO, USA). Sulfalene (100.0\%) was purchased from Fagron NV/SA (Waregem, Belgium). For the preparation of validation standards, a matrix formulation of tablets containing $20 \mathrm{mg}$ of AM and $120 \mathrm{mg}$ of LF was provided by Fourrts laboratories (Kanchipuram, Inde). Mefanther ${ }^{\circledR}$ 20/120 mg tablet were kindly donated by the same laboratories. Antimalarial drugs containing AS and AQ 50/150 were purchased in drugstore located in DRC (Kinshasa). Antimalarial drugs containing AM (20, 40 or $80 \mathrm{mg}$ ) and LF (120, 240 or $480 \mathrm{mg}$ ) were purchased in drugstore located in Benin (Cotonou), DRC (Kinshasa) and Rwanda.

\subsection{Sample Preparation}

\subsubsection{Mixture Preparation Groups}

Individual stock solutions of AM, AS and DHA at $5 \mathrm{mg} / \mathrm{ml}$ and of AQ, PPQ, PM 1mg/ml were prepared in methanol. A stock solution of LF at $100 \mu \mathrm{g} / \mathrm{ml}$ was prepared in methanol acidified by phosphoric acid $(0.1 \%$ acid phosphoric in methanol $(\mathrm{w} / \mathrm{v}))$. Mixture solutions were prepared by diluting stock solutions in methanol-water (50:50, v/v) to achieve the following concentrations: $2.5 \mathrm{mg} / \mathrm{ml}$ for AM, AS, DHA; $50 \mu \mathrm{g} / \mathrm{ml}$ for LF, SL and 25 $\mu \mathrm{g} / \mathrm{ml}$ for PPQ, PM and AQ.

\subsubsection{Solutions Used for Calibration and Validation}

A stock solution of calibration standards (CS) of AM $(240 \mu \mathrm{g} / \mathrm{ml})$ and LF (1440 $\mu \mathrm{g} / \mathrm{ml})$ was prepared in methanol acidified by acid orthophosphoric. A stock solution of AS $(240 \mu \mathrm{g} / \mathrm{mL})$ and AQ $(720 \mu \mathrm{g} / \mathrm{mL})$ was prepared in methanol. Dilutions were performed in methanol-water (50:50) in order to obtain solutions at 3 different concentration levels:

Level 1(40\%): $80 \mu \mathrm{g} / \mathrm{ml}$ (AM) - $480 \mu \mathrm{g} / \mathrm{ml}$ (LF) and $80 \mu \mathrm{g} / \mathrm{ml}$ (AS) - $240 \mu \mathrm{g} / \mathrm{ml}$ (AQ);

Level 3 (80\%): $160 \mu \mathrm{g} / \mathrm{ml}$ (AM) - $960 \mu \mathrm{g} / \mathrm{ml}$ (LF) and $160 \mu \mathrm{g} / \mathrm{ml}$ (AS) - $480 \mu \mathrm{g} / \mathrm{ml}$ (AQ);

Level 5 (120\%): $240 \mu \mathrm{g} / \mathrm{ml}$ (AM) - $1440 \mu \mathrm{g} / \mathrm{ml}$ (LF) and $240 \mu \mathrm{g} / \mathrm{ml}$ (AS) - $720 \mu \mathrm{g} / \mathrm{ml}$ (AQ). 
<smiles>CCN(CC)Cc1cc(Nc2ccnc3cc(Cl)ccc23)ccc1O</smiles>

Amodiaquine<smiles>CCCCN(CCCC)CC(O)c1cc(Cl)cc2c1-c1ccc(Cl)cc1/C2=C/c1ccc(Cl)cc1</smiles>

Lumefantrine

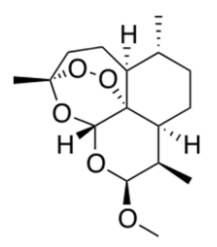

Artemether

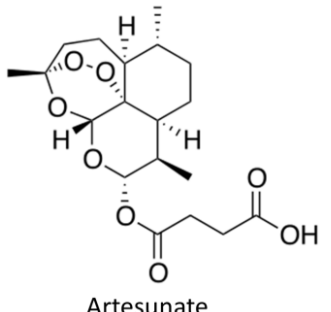

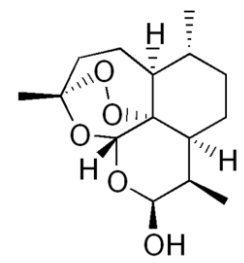

Dihydroartemisinine<smiles>Clc1ccc2c(N3CCN(CCCN4CCN(c5ccnc6cc(Cl)ccc56)CC4)CC3)ccnc2c1</smiles>

Piperaquine<smiles>CCc1nc(N)nc(N)c1-c1ccc(Cl)cc1</smiles>

Pyrimethamine<smiles>COc1nccnc1NS(=O)(=O)c1ccc(N)cc1</smiles>

Sulfalene

Figure 1. Chemical structures of the 8 studied antimalarial drugs.

The levels of the concentration were chosen in order to allow construction of different regression models that will determine back-calculated concentrations of validation standards. For each concentration level three replications were run for three days corresponding to three series $(\mathrm{p}=3)$.

The validation standards were prepared in matrices, here tablets, obtained by the manufacturers of the corresponding medicines in order to better simulate the sample preparation in routine analysis. Stock solutions were obtained as in the case of calibration standards to which is added a corresponding amount of the matrix. Dilutions were performed in methanol-water (50:50) in the same way as described for the CS in order to obtain solutions at 5 different concentration levels.

Level 1 (40\%): $80 \mu \mathrm{g} / \mathrm{ml}$ (AM) - $480 \mu \mathrm{g} / \mathrm{ml}$ (LF) and $80 \mu \mathrm{g} / \mathrm{ml}$ (AS) - $240 \mu \mathrm{g} / \mathrm{ml}$ (AQ);

Level 2 (60\%): $120 \mu \mathrm{g} / \mathrm{ml}$ (AM) - $720 \mu \mathrm{g} / \mathrm{ml}$ (LF) and $120 \mu \mathrm{g} / \mathrm{ml}$ (AS) - $360 \mu \mathrm{g} / \mathrm{ml}$ (AQ);

Level 3 (80\%): $160 \mu \mathrm{g} / \mathrm{ml}$ (AM) - $960 \mu \mathrm{g} / \mathrm{ml}$ (LF) and $160 \mu \mathrm{g} / \mathrm{ml}$ (AS) - $480 \mu \mathrm{g} / \mathrm{ml}$ (AQ);

Level 4 (100\%): $200 \mu \mathrm{g} / \mathrm{ml}$ (AM) - $1200 \mu \mathrm{g} / \mathrm{ml}$ (LF) and $200 \mu \mathrm{g} / \mathrm{ml}$ (AS) - $600 \mu \mathrm{g} / \mathrm{ml}$ (AQ);

Level 5 (120\%): $240 \mu \mathrm{g} / \mathrm{ml}$ (AM) - $1440 \mu \mathrm{g} / \mathrm{ml}$ (LF) and $240 \mu \mathrm{g} / \mathrm{ml}$ (AS) - $720 \mu \mathrm{g} / \mathrm{ml}$ (AQ).

Three independent preparations $(n=3)$ were carried out per each of the five concentration levels $(m=5)$. All these preparations were repeated for three days corresponding also to three series $(\mathrm{p}=3)$.

For routines analyses, the concentrations of reference standards were $200 \mu \mathrm{g} / \mathrm{ml}$ of AM and $1200 \mu \mathrm{g} / \mathrm{mL} \mathrm{of}$ LF in a mixture, $200 \mu \mathrm{g} / \mathrm{ml}$ of AS and $600 \mu \mathrm{g} / \mathrm{mL}$ of AQ in another mixture. For the sample tablets, powdered portions were taken and treated in the same way as reference solutions to give final expected concentrations of $200 \mu \mathrm{g} / \mathrm{ml}$ (AM) - $1200 \mu \mathrm{g} / \mathrm{mL}$ (LF) for AM-LF combination and $200 \mu \mathrm{g} / \mathrm{mL}$ (AS) - $600 \mu \mathrm{g} / \mathrm{mL}$ (AQ) for ASAQ combination. The solutions were freshly prepared and protected from light. They were filtered through 0.45 $\mu \mathrm{m}$ PTFE syringe filtration disks prior to their analysis onto the liquid chromatographic system.

\subsection{Instrumentation and Chromatographic Conditions}

The experiments for optimization of the LC conditions, for the validation work and for the routine analysis were carried out on a LC system from Waters 2695 (Waters, Milford, USA) composed of a Waters selector 7678, autosampler, photodiode array detector (PDA) Waters 2996 and Empower 2.0 software. The analytical column for 
optimization was an XBridge C18 $(250 \times 4.6 \mathrm{~mm}$ i.d.; $5 \mu \mathrm{m}$ particle size $)$ preceded by a guard column XBridge guard C18 $(20 \times 4.6 \mathrm{~mm}$ i.d.; $5 \mu \mathrm{m}$ particle size) both from Waters. The optimized conditions were transferred to an XBridge C18 $(100 \times 4.6$ mm i.d.; $3.5 \mu \mathrm{m}$ particle size $), 4 \mu \mathrm{l}$ for injection volume. Peak analytes were monitored at $230 \mathrm{~nm}$ during optimization and at $210 \mathrm{~nm}$ during validation and routine application. However, the UV spectra were recorded online from $210 \mathrm{~nm}$ to $400 \mathrm{~nm}$ to allow the peak identification at all the experiments. The injection volume was $10 \mu \mathrm{l}$ for all tested experimental conditions. The buffer solution of the isocratic mobile phase consisted of $10 \mathrm{mM}$ ammonium formate $(\mathrm{pKa}=3.8)$ adjusted to $\mathrm{pH}$ of 2.8 with formic acid.

\subsection{Design of Experiments}

Design of experiments (DoE) was used to define the Design of Space (DS). Flow of mobile phase (F), column temperature $\left(\mathrm{T}^{\circ} \mathrm{C}\right)$ and proportion of methanol in the mobile phase $(\% \mathrm{OM})$ were selected as the factors to investigate (see Table 1(a)). As those HPLC methods were developed for their suitability for routine use in resourcerestraint environments, the choice of the methanol as organic modifier was justified by its low cost compare to acetonitrile.

Because of the temperature control problem that might be encountered in that kind of environment we decided to include that factor in the study and to extend the range for test. A total of 29 experimental conditions were defined as shown in Table 1(b). In the present case, a full factorial design was used to allow simultaneous optimization of the method, estimate its robustness and evaluate the adequacy between chromatographic behaviors as predicted by the liquid chromatography theory and those obtained by the mathematical models.

\subsection{Software}

Empower 2.0 for Windows was used to control the HPLC and to record the signals from the detector and interpret the chromatograms. An algorithm was set up to develop a Bayesian model and to compute the DS.

The algorithm was written in R2.13, which is available as free-ware from: http://www.rproject.com.

HPLC calculator V3.0 (University of Geneva, Switzerland) was used to carry out the necessary computations for the geometric transfer methodology.

The accuracy profiles as well as the statistical calculations including the validation results and uncertainty estimates were obtained using e-noval ${ }^{\circledR}$ V3.0 software (Arlenda, Belgium).

\section{Results and Discussion}

\subsection{Modeling and Optimization Methodologies}

\subsubsection{Influence of the Factors on the Peak Separations}

Due to acidic and alkaline comportments of the AAI to test, and considering literature data we choose to perform the experiments in acidic media. Preliminary tests allowed setting the $\mathrm{pH}$ to 2.8 as well as setting up the range and the levels of each factor (see Table 1(a)). They indicated that the retention time of AM was too long (>60 min) with $75 \%$ of methanol in the mobile phase, $\mathrm{pH} 2.5$. To prevent a possible thermal degradation of the different analytes, the maximum temperature for the column oven was limited to $35^{\circ} \mathrm{C}$ while the minimum temperature to $25^{\circ} \mathrm{C}$, the average ambient temperature in tropical countries where further analyses are intended to be pursued.

The influence of the critical factors on the separation of the chromatographic peaks was then assessed by means of full factorial design. As can be noticed in Figure 2, the flow rate and the percentage of organic modifier considerably influence somehow the retention times of AAI: The increase of the mobile phase flow rate as of the organic modifier percentage significantly decreases the retention times of antimalarial drugs, but often at the expense of peak separation. There were also peak coelutions of certain antimalarial compounds and even a reversal of the peak elution order for some others. However, by decreasing the level of these two factors, an increase of the retention times of the tested compounds was observed with improved peak separations. Based on this observation, the ideal would be to work at low level of the flow rate and low percentage of methanol to achieve separation of these antimalarials in this experimental domain.

\subsubsection{Modeling}

For better reliable prediction of the chromatographic conditions of each AAI, modeling was performed using the 
Table 1. (a) Factors and corresponding levels selected for the full factorial design; (b) Experimental matrix of full factorial design for the investigation of organic modifier, flow rate and temperature.

(a)

\begin{tabular}{cccc}
\hline Factors & Levels & \\
\hline Organic modifier $(\%)$ & 80 & 85 & 90 \\
Flow rate (ml/min) & 0.3 & 0.5 & 0.7 \\
Temperature of the column oven $\left({ }^{\circ} \mathrm{C}\right)$ & 25.0 & 30.0 & 35.0 \\
\hline
\end{tabular}

(b)

\begin{tabular}{|c|c|c|c|c|c|c|}
\hline \multirow{2}{*}{ Trial } & \multicolumn{3}{|c|}{ Experimental design } & \multicolumn{3}{|c|}{ Experimental set up } \\
\hline & $\mathrm{X} 1$ & $\mathrm{X} 2$ & $\mathrm{X} 3$ & Organic modifier (\%) & Flow rate $(\mathrm{mL} / \mathrm{min})$ & Temperature $\left({ }^{\circ} \mathrm{C}\right)$ \\
\hline 1 & -1 & -1 & 0 & 80 & 0.3 & 30 \\
\hline 2 & 1 & 0 & 1 & 90 & 0.5 & 35 \\
\hline 3 & 0 & 0 & 0 & 85 & 0.5 & 30 \\
\hline 4 & 1 & -1 & 1 & 90 & 0.3 & 35 \\
\hline 5 & 0 & -1 & 1 & 85 & 0.3 & 35 \\
\hline 6 & -1 & 1 & 1 & 80 & 0.7 & 35 \\
\hline 7 & -1 & 1 & -1 & 80 & 0.7 & 25 \\
\hline 8 & 1 & -1 & 0 & 90 & 0.3 & 30 \\
\hline 9 & 0 & 0 & 0 & 85 & 0.5 & 30 \\
\hline 10 & 0 & 0 & 0 & 85 & 0.5 & 30 \\
\hline 11 & -1 & -1 & -1 & 80 & 0.3 & 25 \\
\hline 12 & 1 & 1 & -1 & 90 & 0.7 & 25 \\
\hline 13 & -1 & 1 & 0 & 80 & 0.7 & 30 \\
\hline 14 & -1 & 0 & 1 & 80 & 0.5 & 35 \\
\hline 15 & 1 & 0 & -1 & 90 & 0.5 & 25 \\
\hline 16 & 0 & 0 & -1 & 85 & 0.5 & 25 \\
\hline 17 & 0 & 0 & 1 & 85 & 0.5 & 35 \\
\hline 18 & 0 & -1 & 1 & 85 & 0.3 & 35 \\
\hline 19 & 0 & -1 & -1 & 85 & 0.3 & 25 \\
\hline 20 & 0 & 1 & 1 & 85 & 0.7 & 35 \\
\hline 21 & -1 & 0 & 0 & 80 & 0.5 & 30 \\
\hline 22 & 1 & 0 & 0 & 90 & 0.5 & 30 \\
\hline 23 & 1 & 1 & 1 & 90 & 0.7 & 35 \\
\hline 24 & 0 & -1 & 0 & 85 & 0.3 & 30 \\
\hline 25 & 1 & -1 & -1 & 90 & 0.3 & 25 \\
\hline 26 & 0 & 1 & 0 & 80 & 0.7 & 30 \\
\hline 27 & -1 & -1 & 1 & 85 & 0.3 & 35 \\
\hline 28 & 1 & 1 & 0 & 90 & 0.7 & 30 \\
\hline 29 & -1 & 0 & -1 & 80 & 0.5 & 25 \\
\hline
\end{tabular}

retention time of each strategic part of the chromatographic peak, i.e. the beginning, the apex and the end [10][13]. The quality of the obtained linear regressions was assessed by the adjusted coefficient of determination $\left(\mathrm{R}^{2}\right.$ ajusted), the graph residues and the adequacy between the retention times predicted by the model and those observed. As shown in Figure 3(a), an excellent relationship was observed between the predicted versus the experimental values of the retention times ( $\mathrm{R}^{2}$ adjusted values close to 1 ). In addition, most of the residuals (Figure 3 (b)) were located within the $[-1.5 \mathrm{~min},+1.5 \mathrm{~min}]$ interval, confirming the fitness of the model and its suitability for the optimization of the separation. 


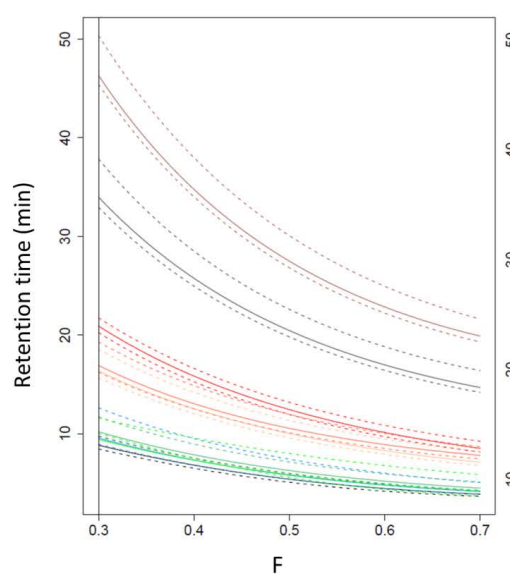

(a)

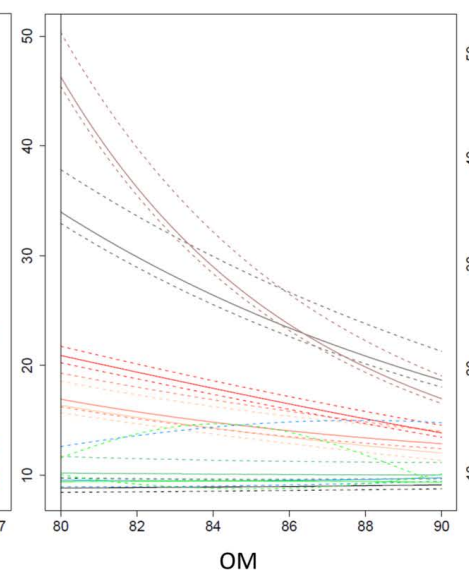

(b)

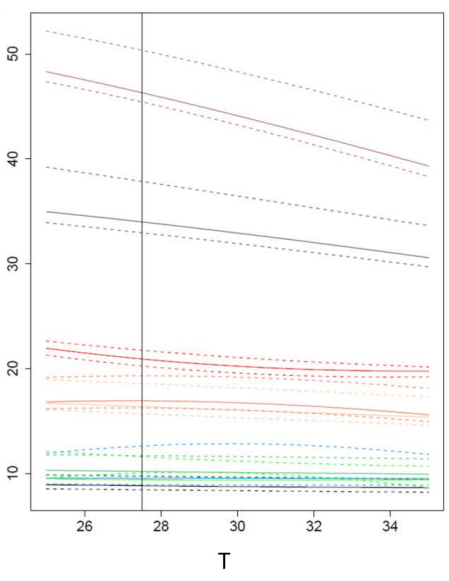

(c)

Figure 2. Predicted retention times (min) of different compounds versus to flow rate (F) (a), to organic modifier (OM) (b) and to temperature $(\mathrm{T})(\mathrm{c})$.

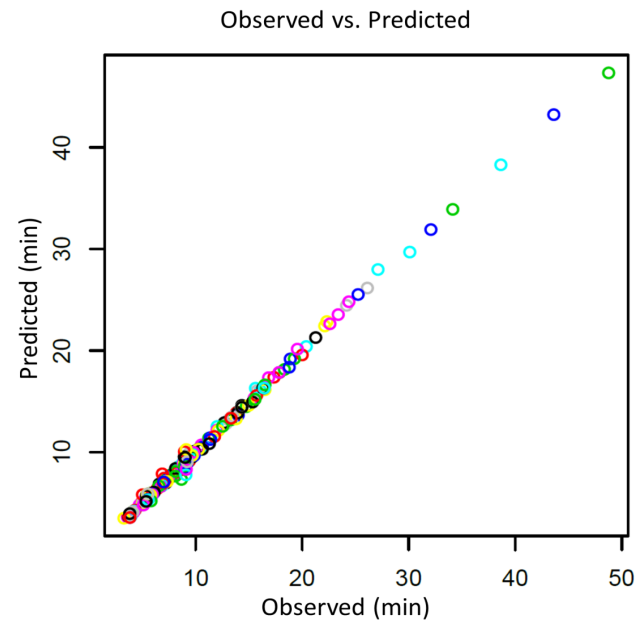

(a)

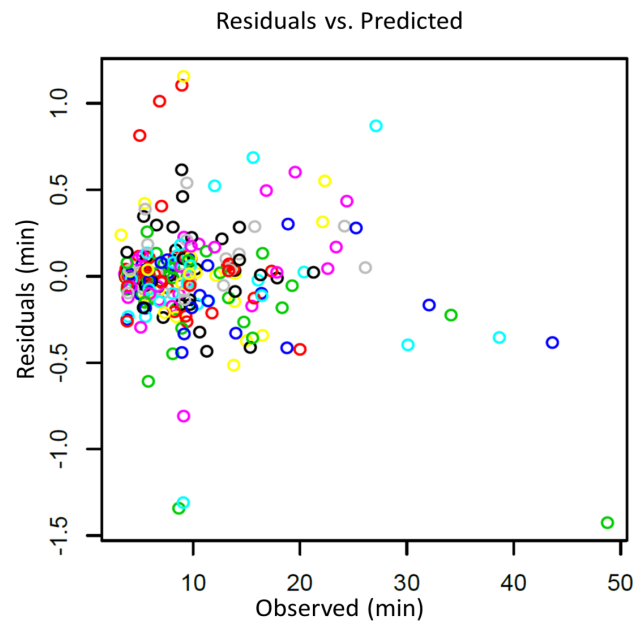

(b)

Figure 3. Modelling results (a) Predicted versus experimental values for retention times; (b) Corresponding residuals plots.

\subsubsection{Prediction of Optimal Separations}

The good relationship between the predicted retention times and those obtained allowed validating the linear regression model and optimizing selected criteria. The separation between the peaks of the critical pair has been chosen as a critical quality attribute (CQA) for the evaluation of quality chromatogram [8]. As proposed by Lebrun et al. [8] [10] we used in this work the separation criterion $(S)$ defined as the difference between the beginning of the second eluting peak $\left(t_{\mathrm{RB}}\right)$ and the end of the first eluting peak $\left(\mathrm{t}_{\mathrm{RE}}\right)$ of the critical peak pair.

Over the experimental domain, as shown on Figure 4, the probability of peak separation P $(S>0)$ was low: $0.4 \%$. Due to the very similar chromatographic behavior of some AAI, the tested experimental domain $(\mathrm{F}=0.3$ $\mathrm{mL} / \mathrm{min}, \mathrm{T}=27.5^{\circ} \mathrm{C}, \% \mathrm{OM}=80 \%$ ) did not allow a simultaneous separation of all AAI peaks. This was the case of AQ, SL PM, DHA, AS, PPQ as shown in Figure 5.

This low probability of peak separation led us to split molecules with similar chromatographic behavior in 4 separated groups (Table 2) while Group 5 was constituted by WHO's recommended ACTs drugs marketed in Africa.

These five groups were experimented with the same design tested before applying the same corresponding factors levels as mentioned in Table 1. The optimal conditions for each group and quality level are given in Table 3 including the quite large operating range within DS that indicates the robustness of the method for each group. 


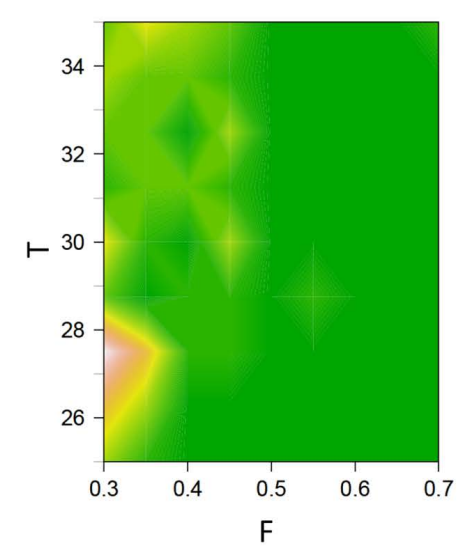

(a)

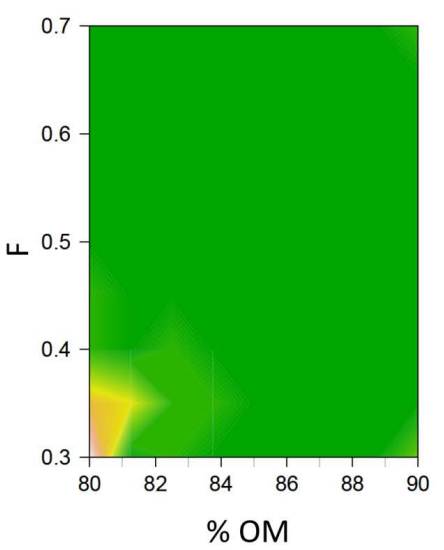

(b)

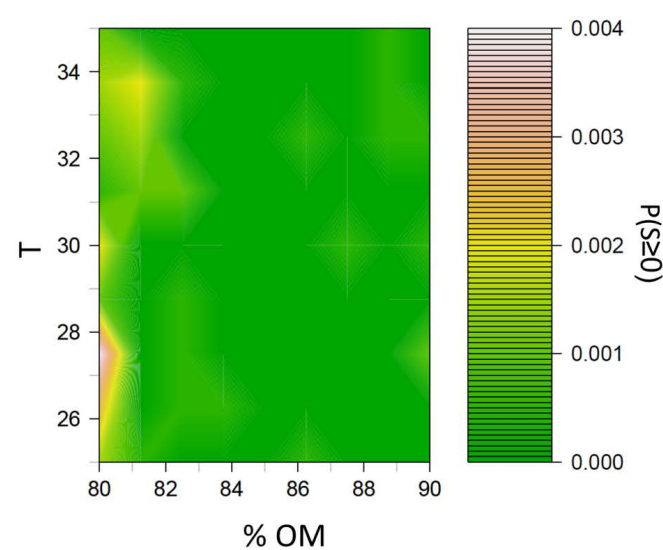

(c)

Figure 4. Probability surfaces to reach $S \geq 0$. (a) Temperature $\left({ }^{\circ} \mathrm{C}\right.$ ) versus Flow rate $(\mathrm{ml} / \mathrm{min})$; (b) Flow rate (ml/min) versus Organic modifier (\%); (c) Temperature $\left({ }^{\circ} \mathrm{C}\right)$ versus organic modifier $(\%)$.

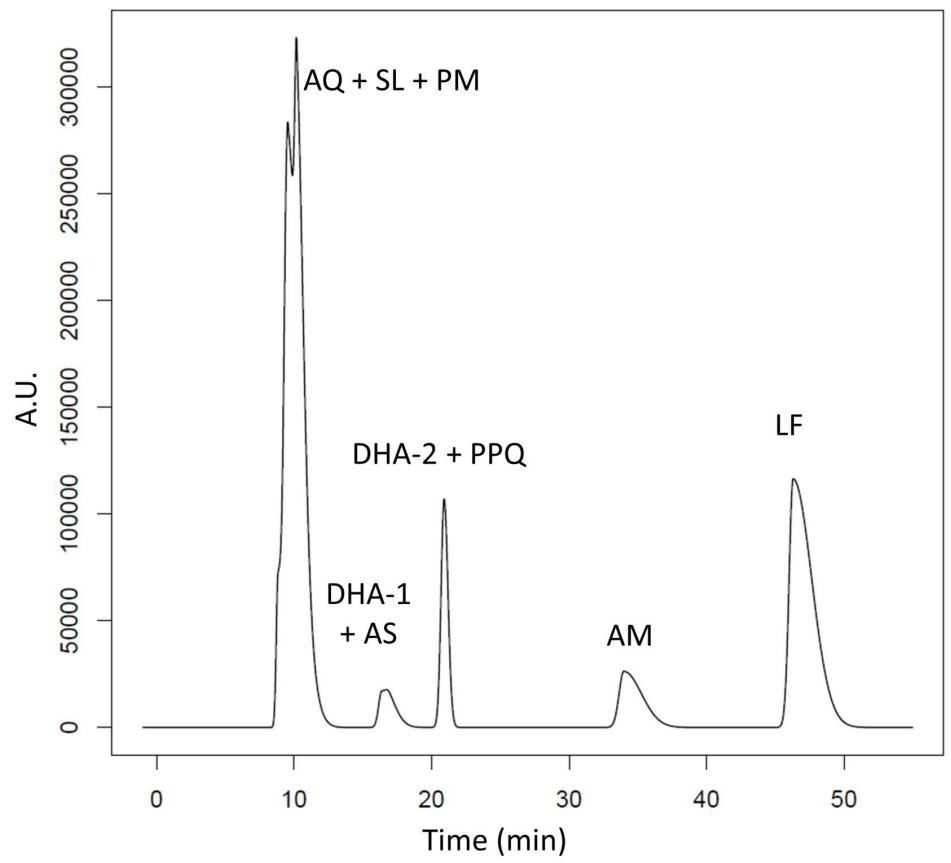

Figure 5. Predicted chromatogram at optimal conditions for 8 antimalarials.

Table 2. Groups of compounds studied in this work.

\begin{tabular}{ccc} 
Group & Subgroups & Molecules \\
\hline Group 1 & - & AM, LF, DHA-1, DHA-2 and PPQ \\
Group 2 & - & AM, LF, AS and AQ \\
Group 3 & - & AM, LF, DHA-1, DHA-2 and PM \\
Group 4 & - & AM, LF, AS and SL \\
Group 5 & 1 & AM and LF \\
& 2 & AS and AQ \\
\hline
\end{tabular}

Legend: $\mathrm{AM}=$ Artemether, $\mathrm{LF}=$ Lumefantrine, $\mathrm{DHA}=$ Dihydroartemisinin, $\mathrm{PPQ}=$ Piperaquine, $\mathrm{AS}=$ Artesunate, $\mathrm{AQ}=$ Amodiaquine, $\mathrm{PM}=\mathrm{Pyri}-$ methamine, SL = Sulfalene. 
Table 3. Optimal conditions and operating range within DS for the separation of the 5 groups of antimalarial.

\begin{tabular}{|c|c|c|c|c|c|c|}
\hline \multicolumn{6}{|c|}{ Optimal condition by group } & \multirow{3}{*}{$\begin{array}{c}\text { Final optimal } \\
\text { conditions }\end{array}$} \\
\hline \multicolumn{2}{|c|}{ Optimal conditions } & \multirow{2}{*}{$\begin{array}{l}\text { Optimal } \\
\mathrm{P}(S>0)\end{array}$} & \multirow{2}{*}{$\begin{array}{c}\text { Flow rate } \\
\text { (F in } \mathrm{mL} / \mathrm{min} \text { ) }\end{array}$} & \multirow{2}{*}{$\begin{array}{l}\text { Organic modifier } \\
\text { (OM in \%) }\end{array}$} & \multirow{2}{*}{$\begin{array}{l}\text { Temperature } \\
\left(\mathrm{T} \text { in }{ }^{\circ} \mathrm{C}\right)\end{array}$} & \\
\hline Groups & Subgroups & & & & & \\
\hline 1 & - & $68.0 \%$ & $\begin{array}{c}0.45 \\
(0.45-0.61)\end{array}$ & $\begin{array}{c}81.3 \\
(80.0-82.1)\end{array}$ & $\begin{array}{c}25.0 \\
(25.0-35.0)\end{array}$ & \multirow{4}{*}{$\begin{array}{c}\text { OM: } 80.0 \% \\
\text { F: } 0.5 \mathrm{~mL} / \mathrm{min} \\
\mathrm{T}: 25^{\circ} \mathrm{C}\end{array}$} \\
\hline 2 & - & $99.5 \%$ & $\begin{array}{c}0.70 \\
(0.55-0.70)\end{array}$ & $\begin{array}{c}80.0 \\
(80.0-81.8)\end{array}$ & $\begin{array}{c}32.5 \\
(25.0-34.5)\end{array}$ & \\
\hline 3 & - & $73.0 \%$ & $\begin{array}{c}0.45 \\
(0.41-6.50)\end{array}$ & $\begin{array}{c}81.3 \\
(81.0-82.1)\end{array}$ & $\begin{array}{c}25.0 \\
(25.0-27.0)\end{array}$ & \\
\hline 4 & - & $92.9 \%$ & $\begin{array}{c}0.65 \\
(0.48-7.00)\end{array}$ & $\begin{array}{c}80.0 \\
(80.0-81.5)\end{array}$ & $\begin{array}{c}32.5 \\
(25.0-35.0)\end{array}$ & \\
\hline \multirow{2}{*}{5} & 1 & $98.5 \%$ & $\begin{array}{c}0.70 \\
(0.61-0.70)\end{array}$ & $\begin{array}{c}81.3 \\
(80.5-82.0)\end{array}$ & $\begin{array}{c}26.3 \\
(25.0-35.0)\end{array}$ & \multirow{2}{*}{$\begin{array}{c}\text { OM: } 82.5 \% \\
\text { F: } 0.6 \mathrm{~mL} / \mathrm{min} \\
\mathrm{T}: 25^{\circ} \mathrm{C}\end{array}$} \\
\hline & 2 & $99.9 \%$ & $\begin{array}{c}0.40 \\
(0.55-0.70)\end{array}$ & $\begin{array}{c}88.8 \\
(87.5-90.0)\end{array}$ & $\begin{array}{c}25.0 \\
(25.0-35.0)\end{array}$ & \\
\hline
\end{tabular}

One can say that a large temperature robust range $\left(25^{\circ} \mathrm{C}\right.$ to $35^{\circ} \mathrm{C}$, except for Group $3\left(25^{\circ} \mathrm{C}\right.$ to $\left.\left.27^{\circ} \mathrm{C}\right)\right)$ is important for applying easily the methods in the laboratories without an efficient temperature control system that is often met in resource-restraint environments.

In order to facilitate the screening of AAI in Groups 1 to 4, a single method was generated by computing DS obtained only for these groups. One single method was also generated for Groups 5.1 and 5.2. The optimal conditions are given in Table 3.

To support the ability of DS to predict analytical conditions that permit chromatographic separation for the AAI in the 5 groups, we tested the mixture of these AAI in each optimal condition using an XBridge C18 (250 $\times$ $4.6 \mathrm{~mm}$ i.d.; $5 \mu \mathrm{m}$ particle size $)$, preceded by a guard column XBridge guard C18 $(20 \times 4.6 \mathrm{~mm}$ i.d.; $5 \mu \mathrm{m}$ particle size). The experimental and the predicted chromatograms are given in Figures 6-11 where it can be noticed a close agreement between the different predicted chromatograms and the corresponded experimental ones.

The correlation between the predicted retention times and observed for the chromatograms recorded at the optimal condition was very good. Indeed, in all cases, the linear correlation coefficient was very close to the unit, validating the accuracy of the prediction. Concerning the two WHO's recommended ACTs, the liquid chromatography method developed for the simultaneous quantification offered the advantage of being used in isocratic mode, unlike the methods of the American pharmacopoeia and international pharmacopoeia offering the gradient mode and are time consuming [14] [15].

In order to reduce the analysis time and thus the solvent consumption, the geometric transfer was performed for each developed method following geometric transfer methodology while checking their robustness [16]. The corresponding analytical conditions were: $4 \mu \mathrm{l}$ for injection volume, $0.6 \mathrm{~mL} / \mathrm{min}$ for the flow rate, $82.5 \%$ for the organic modifier, $17.5 \%$ for the buffer. The buffer solution of the isocratic mobile phase consisted of $10 \mathrm{mM}$ ammonium formate (pKa 3.8) adjusted at $\mathrm{pH}$ of 2.8 with formic acid and $25^{\circ} \mathrm{C}$ for the oven temperature of the column whose characteristics are described at Section 3.2.

The chromatograms in Figures 6-11 and the results in Table 4 demonstrated the adequate geometric transfer. Indeed, both relative predicted retention times and observed ones were closer for AM, LF, AS, AQ applying the separation conditions before and after geometric transfer. The transferred methods were reduced of about half the run time and obviously a half reduction of the solvent consumption.

It was found important to highlight that the same optimal condition can be used to analyze dihydroartemisinin-piperaquine because of the very good separation observed (data not shown). By cons, the optimized method cannot be used to analyze the associations such as sulfalene-pyrimethamine-dihydroartemisinin and artesunatesulfalene-pyrimethamine, due to the co-elution of the chromatographic peaks corresponding to sulfalene and pyrimethamine. These associations of antimalarial drugs are also marketed in certain African countries.

\subsection{Method Validation}

In current practice, after the optimization step, it becomes increasingly obvious and essential to demonstrate 


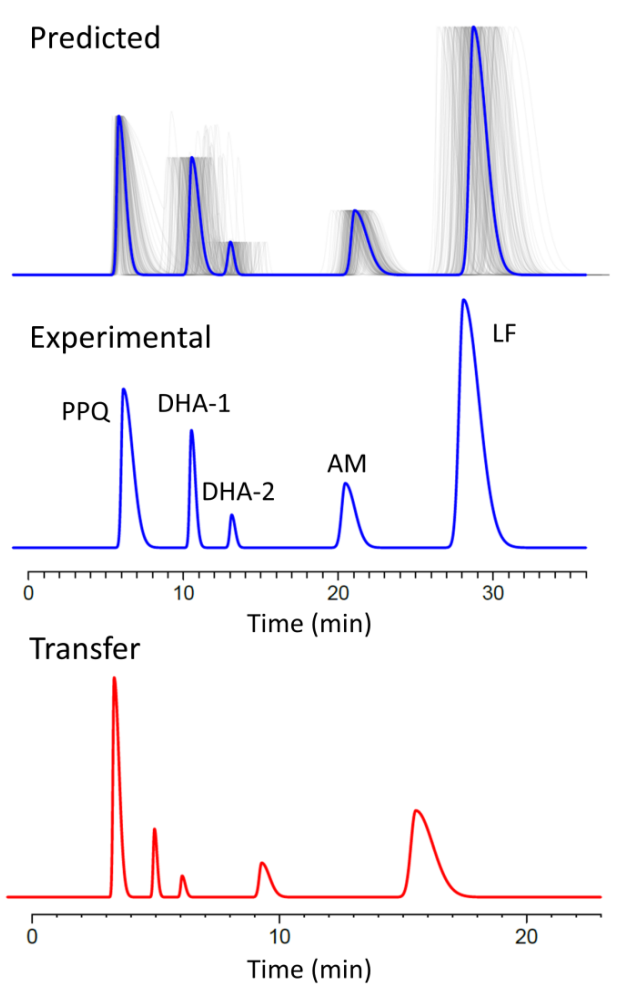

Figure 6. Optimal condition for Group 1: (top) predicted chromatogram, Grey: simulations showing the uncertainty of prediction; (middle) observed chromatogram and (bottom) observed chromatogram resulting of the transfer.

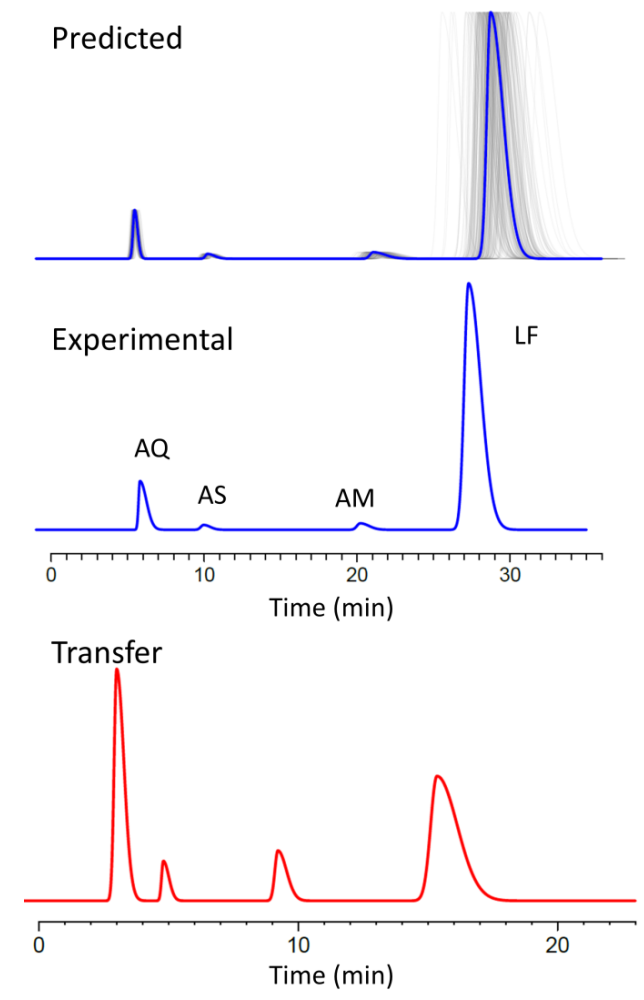

Figure 7. Optimal condition for Group 2: (top) predicted chromatogram, Grey: simulations showing the uncertainty of prediction; (middle) observed chromatogram and (bottom) observed chromatogram resulting of the transfer. 

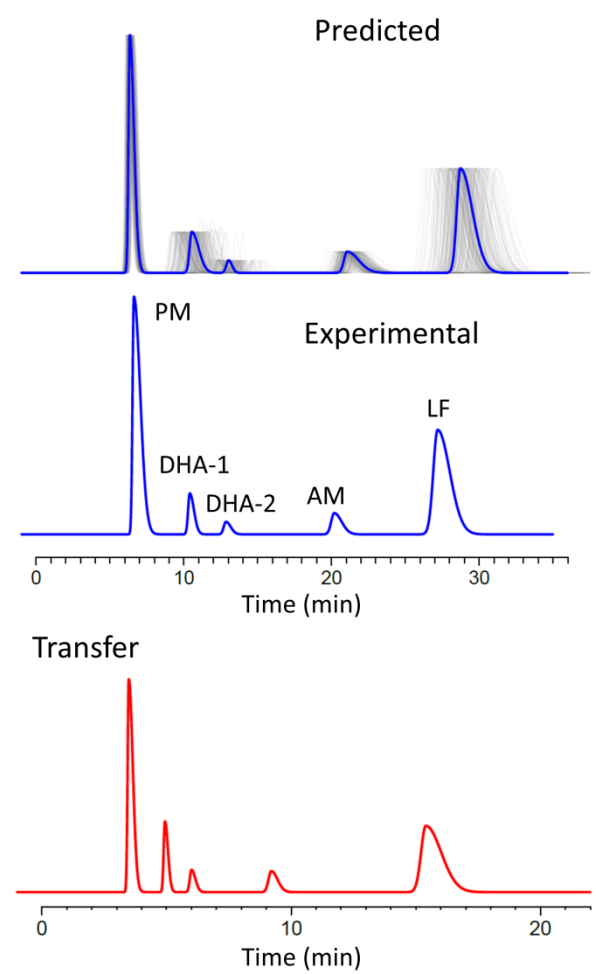

Figure 8. Optimal condition for Group 3: (top) predicted chromatogram, Grey: simulations showing the uncertainty of prediction; (middle) observed chromatogram and (bottom) observed chromatogram resulting of the transfer.
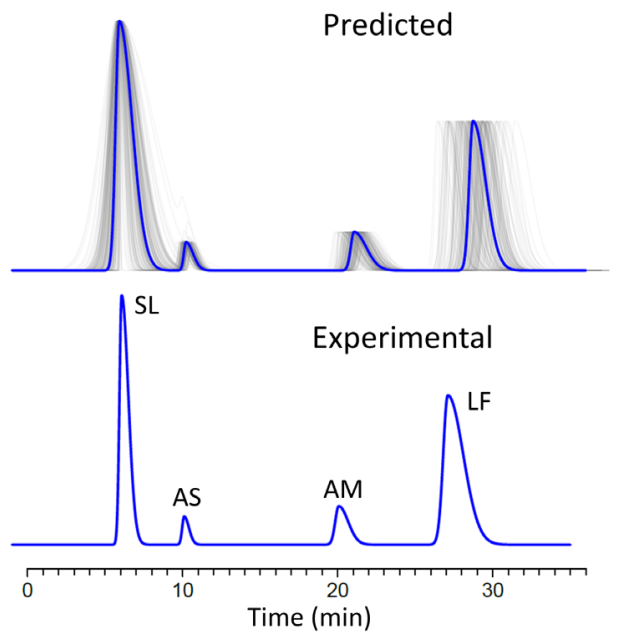

Transfer

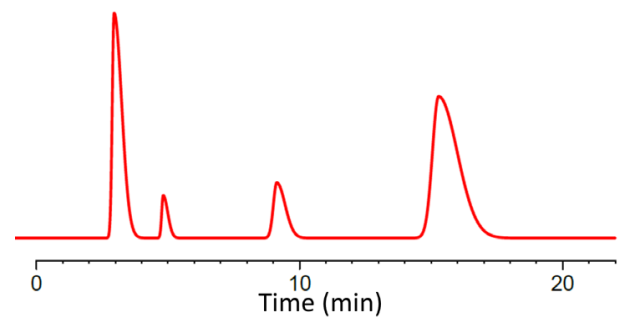

Figure 9. Optimal condition for Group 4: (top) predicted chromatogram, Grey: simulations showing the uncertainty of prediction; (middle) observed chromatogram and (bottom) observed chromatogram resulting of the transfer. 

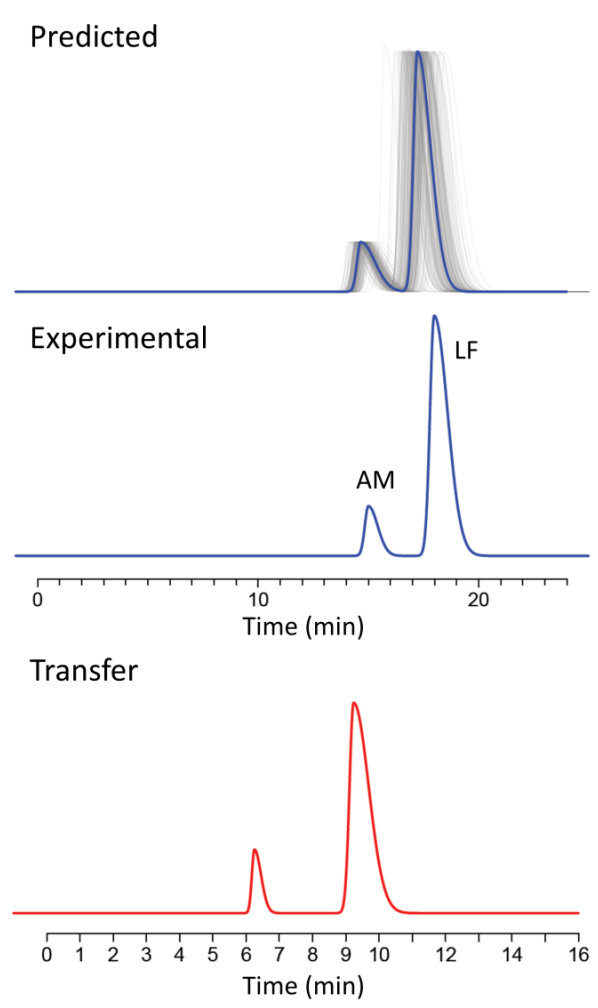

Figure 10. Optimal condition for Group 5.1: (top) predicted chromatogram, Grey: simulations showing the uncertainty of prediction; (middle) observed chromatogram and (bottom) observed chromatogram resulting of the transfer.

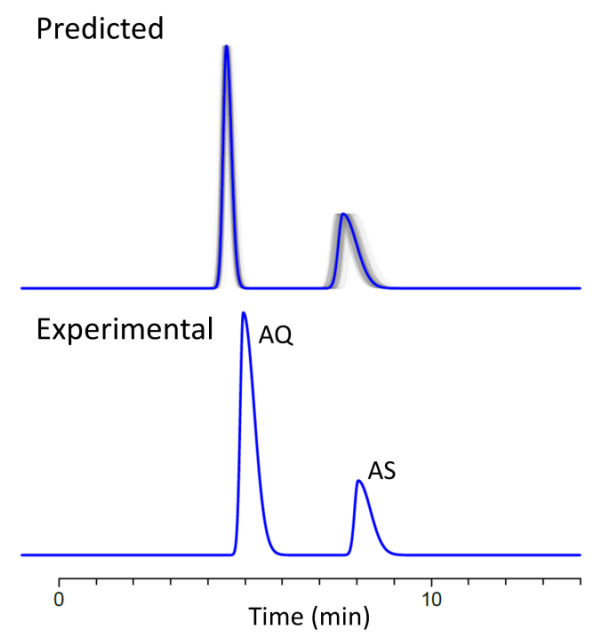

Transfer

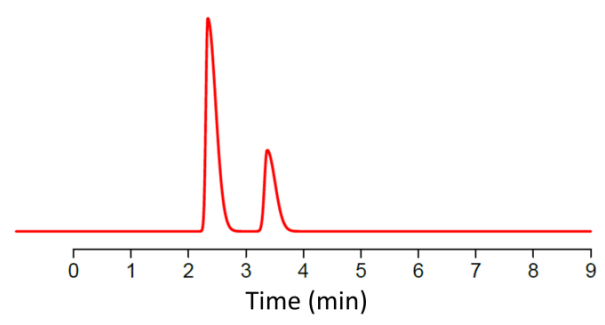

Figure 11. Optimal condition for Group 5.2: (top) predicted chromatogram, Grey: simulations showing the uncertainty of prediction; (middle) observed chromatogram and (bottom) observed chromatogram resulting of the transfer. 
Table 4. Results of the method geometric transfer.

\begin{tabular}{cccccccc}
\hline & \multicolumn{3}{c}{ HPLC Optimal } & \multicolumn{2}{c}{ HPLC Transfer } & $\begin{array}{c}\text { Relative } \\
\text { observed }\end{array}$ \\
\cline { 2 - 5 } Compounds & $\begin{array}{c}\text { Predicted } \\
\text { retention } \\
\text { times }\end{array}$ & $\begin{array}{c}\text { Observed } \\
\text { retention } \\
\text { times }\end{array}$ & $\begin{array}{c}\text { Relative } \\
\text { predicted } \\
\text { retention } \\
\text { times }\end{array}$ & $\begin{array}{c}\text { Relative } \\
\text { observed } \\
\text { retention } \\
\text { times }\end{array}$ & $\begin{array}{c}\text { Observed } \\
\text { retention } \\
\text { times }\end{array}$ & $\begin{array}{c}\text { Relative } \\
\text { observed } \\
\text { retention } \\
\text { times }\end{array}$ & $\begin{array}{c}\text { retention times } \\
\text { error }\end{array}$ \\
AM & 21.529 & 20.335 & 0.791 & 0.746 & 8.572 & 0.572 & 0.184 \\
AQ & 5.505 & 5.270 & 0.202 & 0.193 & 2.297 & 0.153 & 0.040 \\
AS & 10.142 & 9.731 & 0.373 & 0.357 & 4.006 & 0.268 & 0.089 \\
DHA-1 & 11.016 & 10.032 & 0.405 & 0.368 & 4.100 & 0.274 & 0.094 \\
DHA-2 & 13.946 & 12.662 & 0.513 & 0.464 & 5.226 & 0.349 & 0.115 \\
LF & 27.195 & 27.274 & 1.000 & 1.000 & 14.976 & 1.000 & 0.000 \\
PM & 6.724 & 6.087 & 0.247 & 0.223 & 2.621 & 0.175 & 0.048 \\
PPQ & 6.486 & 5.680 & 0.238 & 0.208 & 2.461 & 0.164 & 0.044 \\
SL & 5.966 & 5.686 & 0.219 & 0.208 & 2.159 & 0.144 & 0.064 \\
\hline
\end{tabular}

through a method validation that optimized method provides reliable results. In this work, the transferred method was also validated using the accuracy profile as decision tool and for the simultaneous quantitation of the couples artemether/lumefantrine and artesunate/amodiaquine in fixed dose combination (FDC) tablets [17] [18]. We considered the validation criteria commonly used in analytical procedures set out in document Q2A of the International Conference on Harmonization (ICH) [19] namely: selectivity/ specificity, trueness, precision (repeatability and intermediate precision), accuracy, linearity, limit of detection (LOD) and limit of quantitation (LOQ).

An analytical method is specific if it guarantees that the measured signal is only related to the substance intended to be analyzed (targeted compound) and if it allows quantitation of a physicochemical parameter or a chemical group from a single or several substance(s) in the sample [20]. The non-interference of the ingredients present in the matrix was assessed by injecting matrix solutions of each formulation provided by manufacturer and solution containing mixture of targeted compound (AM, LF, AS, AQ). Absence of any interference was noted.

Secondly, we investigated the response function of the method. It is the existing relationship between the response (signal) and the concentration (quantity) of the analyte sample within the range of concentrations tested. The calibration curve was the most appropriate response function. Table 5 presents the most appropriate selected regression models that have been sorted according to the accuracy index.

The selected calibration model is linear regression due to his high level of accuracy index. The concentrations results were back-calculated using the calibration curves. These concentrations were used to determine the relative bias, the precision (repeatability and intermediate precision), the $\beta$-expectation tolerance intervals at $95 \%$ probability level, and the linearity. The accuracy profiles for the four compounds are given in Figure 12 while the validation criteria are summarized in Table 6 .

The acceptance limits have been set at $\pm 10 \%$ according to the International Pharmacopeia and the intended use of the analytical procedure [15].

Trueness refers to the closeness of agreement between a conventionally accepted value or reference value and a mean experimental one. It gives information on systematic error. As shown in Table 6, trueness was expressed in terms of absolute bias (in $\mu \mathrm{g} / \mathrm{mL}$ ) or relative bias (\%) at each concentration level of the validation standards. The trueness of the developed method is good with the absolutes biases and relative biases less than 6\% (Table 6).

Precision is the closeness of agreement among measurements from multiple sampling of a homogeneous sample under the recommended conditions. It gives some information on random errors and it can be evaluated at two levels: repeatability and intermediate precision. As can be seen in Table 6, precision was expressed in terms of relative standard deviation values for repeatability and for intermediate precision that were below 3.3\%. This indicates a good precision of the developed method.

The linearity of an analytical method is the ability within a definitive range to obtain results directly proportional to the concentration (quantity) of the analyte in the sample. A linear regression model is fitted on the 
Table 5. Evaluation of quality of fit for the selected regression model for artemether, lumefantrine, artesunate and amodiaquine.

\begin{tabular}{|c|c|c|c|c|c|}
\hline \multirow{2}{*}{ Active ingredient } & \multirow{2}{*}{ Model } & \multicolumn{4}{|c|}{ Indexes for: } \\
\hline & & Precision & Trueness & Dosing range & Accuracy \\
\hline \multirow{4}{*}{ Artemether } & Linear regression through 0 fitted using the highest level only & 0.830 & 0.746 & 0.414 & 0.635 \\
\hline & Linear regression through 0 fitted using the level 1.0 only & 0.662 & 0.866 & 0.569 & 0.688 \\
\hline & Weighted $(1 / \mathrm{X})$ linear regression & 0.461 & 0.970 & 1.000 & 0.765 \\
\hline & Linear regression & 0.485 & 0.962 & 0.982 & 0.771 \\
\hline \multirow{4}{*}{ Lumefantrine } & Linear regression through 0 fitted using the highest level only & 0.763 & 0.864 & 0.498 & 0.690 \\
\hline & Linear regression through 0 fitted using the level 1.0 only & 0.657 & 0.845 & 1.000 & 0.828 \\
\hline & Weighted $(1 / \mathrm{X})$ linear regression & 0.674 & 0.868 & 0.645 & 0.723 \\
\hline & Linear regression & 0.648 & 0.864 & 1.000 & 0.824 \\
\hline \multirow{4}{*}{ Artesunate } & Linear regression through 0 fitted using the highest level only & 0.725 & 0.957 & 0.944 & 0.869 \\
\hline & Linear regression through 0 fitted using the level 1.0 only & 0.713 & 0.952 & 0.999 & 0.878 \\
\hline & Weighted $(1 / \mathrm{X})$ linear regression & 0.689 & 0.974 & 0.997 & 0.874 \\
\hline & Linear regression & 0.713 & 0.952 & 1.000 & 0.877 \\
\hline \multirow{4}{*}{ Amodiaquine } & Linear regression through 0 fitted using the highest level only & 0.884 & 0.001 & 0.521 & 0.001 \\
\hline & Linear regression through 0 fitted using the level 1.0 only & 0.931 & 0.001 & 0.157 & 0.001 \\
\hline & Weighted $(1 / \mathrm{X})$ linear regression & 0.662 & 0.996 & 1.000 & 0.870 \\
\hline & Linear regression & 0.660 & 0.996 & 1.000 & 0.870 \\
\hline
\end{tabular}

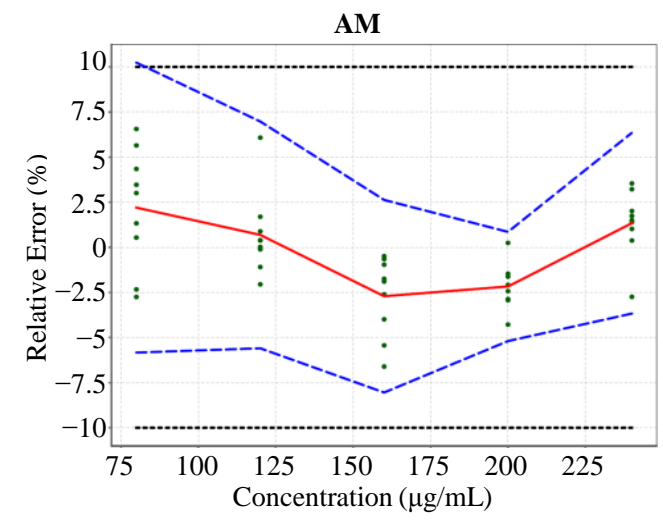

AS

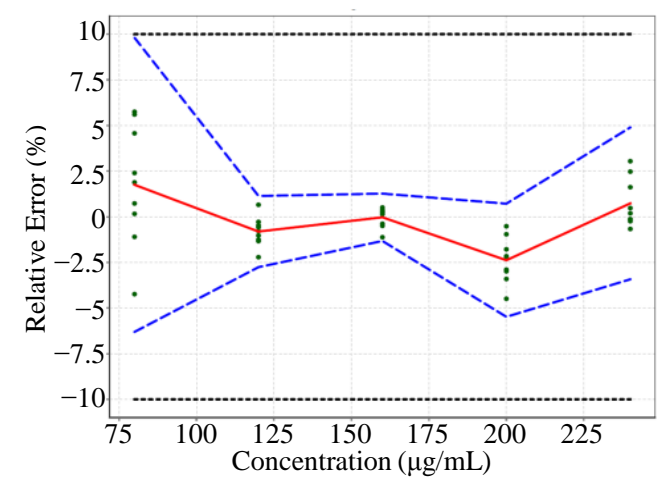

LF

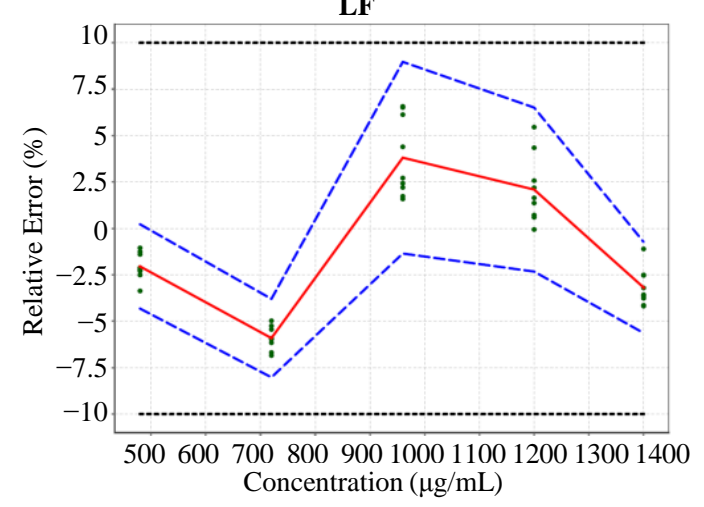

AQ

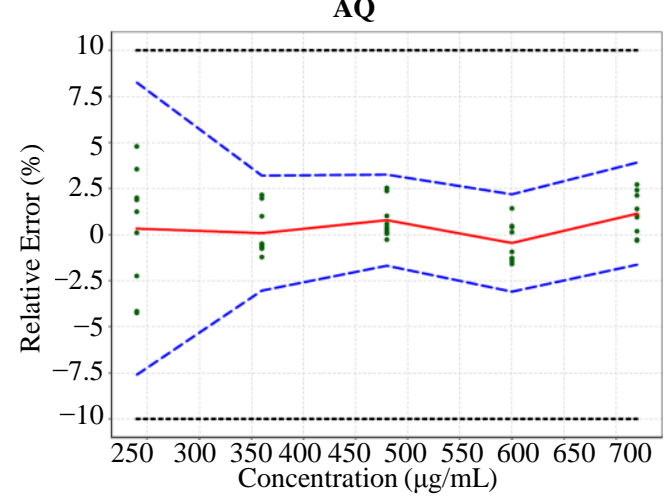

Figure 12. Accuracy profiles for quantitative methods validation of artemether (AM) and lumefantrine (LF) in tablet and of artesunate (AS) and amodiaquine (AQ) in tablet. The plain red line represents the relative bias, the dashed lines the 95\% $\beta$-expectation tolerance limits and the dotted lines the $10 \%$ acceptance limits. The dots express the relative error of the backcalculated concentrations plotted with respect to their targeted concentration. 
Table 6. Summary of the validation criteria for artemether, lumefantrine, artesunate and amodiaquine.

\begin{tabular}{|c|c|c|c|c|c|}
\hline \multirow{2}{*}{ Validation Criteria } & \multirow{2}{*}{ Level } & \multicolumn{2}{|c|}{ Artemether-Lumefantrine } & \multicolumn{2}{|c|}{ Artesunate-Amodiaquine } \\
\hline & & Artemether & Lumefantrine & Artesunate & Amodiaquine \\
\hline \multirow{6}{*}{$\begin{array}{c}\text { Trueness: } \\
\text { Absolute bias }(\mu \mathrm{g} / \mathrm{mL}) \\
\text { (Relative bias }(\%) \text { ) }\end{array}$} & 1 & $1.76(2.20)$ & $-9.83(-2.05)$ & $1.40(1.74)$ & $0.79(0.33)$ \\
\hline & 2 & $0.83(0.69)$ & $-42.54(-5.91)$ & $-0.97(-0.81)$ & $0.33(0.08)$ \\
\hline & 3 & $-4.34(-2.71)$ & 36.58 (3.81) & $-0.04(-0.03)$ & $3.78(0.79)$ \\
\hline & 4 & $-4.34(-2.17)$ & $25.12(2.09)$ & $-4.76(-2.38)$ & $-2.71(-0.45)$ \\
\hline & 5 & $3.22(1.34)$ & $-44.56(-3.18)$ & $1.77(0.74)$ & $8.21(-0.33)$ \\
\hline & 1 & $3.28 / 3.28$ & $0.56 / 0.77$ & $3.29 / 3.29$ & $3.24 / 3.24$ \\
\hline \multirow{4}{*}{$\begin{array}{l}\text { Precision: } \\
\text { Repeatability (RSD in \%)/ } \\
\text { Intermediate precision } \\
\text { (RSD in \%) }\end{array}$} & 2 & $2.04 / 2.37$ & $0.44 / 0.67$ & $0.80 / 0.80$ & $1.28 / 1.28$ \\
\hline & 3 & $2.18 / 2.18$ & $2.11 / 2.11$ & $0.53 / 0.53$ & $1.01 / 1.01$ \\
\hline & 4 & $1.24 / 1.24$ & $1.81 / 1.81$ & $1.19 / 1.24$ & $1.08 / 1.08$ \\
\hline & 5 & $1.63 / 1.89$ & $0.97 / 0.99$ & $1.03 / 1.41$ & $1.13 / 1.33$ \\
\hline \multirow{5}{*}{$\begin{array}{c}\text { Accuracy: } \\
\beta \text {-expectation tolerance } \\
\text { interval (in } \mu \mathrm{g} / \mathrm{mL} \text { ) } \\
\text { (Relative } \beta \text {-expectation } \\
\text { tolerance interval (in \%)) }\end{array}$} & 1 & $\begin{array}{l}75.33-88.19 \\
(-5.83 / 10.24)\end{array}$ & $\begin{array}{c}459.30-481.10 \\
(-4.32 / 0.22)\end{array}$ & $\begin{array}{c}74.96-87.85 \\
(-6.31 / 9.81)\end{array}$ & $\begin{array}{c}221.80-259.80 \\
(-7.60 / 8.26)\end{array}$ \\
\hline & 2 & $\begin{array}{c}113.30-128.40 \\
(-5.60 / 6.97)\end{array}$ & $\begin{array}{c}662.20-692.70 \\
(-8.02 /-3.80)\end{array}$ & $\begin{array}{c}116.70-121.40 \\
(-2.76 / 1.14)\end{array}$ & $\begin{array}{c}349.10-371.50 \\
(-3.04 / 3.21)\end{array}$ \\
\hline & 3 & $\begin{array}{c}147.10-164.2 \\
(-8.05 / 2.63)\end{array}$ & $\begin{array}{c}947.00-1046.00 \\
(-1.35 / 8.97)\end{array}$ & $\begin{array}{c}157.90-162.00 \\
(-1.32 / 1.27)\end{array}$ & $\begin{array}{c}471.90-495.60 \\
(-1.68 / 3.26)\end{array}$ \\
\hline & 4 & $\begin{array}{c}189.60-201.70 \\
(-5.20 / 0.86)\end{array}$ & $\begin{array}{c}1172.00-1278.00 \\
(-2.32 / 6.51)\end{array}$ & $\begin{array}{c}189.00-201.40 \\
(-5.48 / 0.72)\end{array}$ & $\begin{array}{c}581.40-613.10 \\
(-3.09 / 2.19)\end{array}$ \\
\hline & 5 & $\begin{array}{c}231.2-255.2 \\
(-3.67 / 6.35)\end{array}$ & $\begin{array}{c}1321.00-1390.00 \\
(-5.64 /-0.73)\end{array}$ & $\begin{array}{c}231.00-251.30 \\
(-3.42 / 4.90)\end{array}$ & $\begin{array}{c}708.30-748.20 \\
(-1.63 / 3.91)\end{array}$ \\
\hline \multirow{5}{*}{$\begin{array}{c}\text { Uncertainty: } \\
\text { Relative expanded } \\
\text { uncertainty (\%) }\end{array}$} & 1 & 6.92 & 1.69 & 6.94 & 6.83 \\
\hline & 2 & 5.12 & 1.49 & 1.68 & 2.69 \\
\hline & 3 & 4.60 & 4.45 & 1.12 & 2.13 \\
\hline & 4 & 2.61 & 3.81 & 2.64 & 2.28 \\
\hline & 5 & 4.09 & 2.10 & 3.10 & 2.39 \\
\hline \multirow{3}{*}{ Linearity: } & Slope & 0.994 & 1.002 & 0.992 & 1.010 \\
\hline & Intercept & 0.329 & -8.938 & 0.703 & -2.659 \\
\hline & $\mathrm{R}^{2}$ & 0.994 & 0.988 & 0.997 & 0.998 \\
\hline
\end{tabular}

back-calculated concentrations as a function of the introduced concentrations. The good linearity of the results was illustrated (Table 6) by the slopes close to 1 of the regression models obtained between the introduced and the back-calculated concentrations.

Accuracy refers to the closeness of agreement between the test result and the accepted reference value, namely the conventionally true value. The accuracy takes into account the total error, i.e. systematic and random errors, related to the test result. It is assessed from the accuracy profile illustrated in Figure 12. An accuracy profile is obtained by linking on one hand the lower bounds and on the other hand the upper bounds of the $\beta$-expectation tolerance intervals calculated at each concentration level. As shown in Table 6, the relative $\beta$-expectation tolerance intervals are generally within a range of $[-0.73,9.81 \%]$ excepted Level 1 for AM. As the lower and upper tolerance bounds are included within the acceptance limits for all the targeted concentration levels (excepted Level 1 for AM), one can ensure that each future result will fall within the acceptance range with a probability of at least 95\% [21] [22].

The limit of detection (LOD) is the smallest quantity of the targeted substance that can be detected, but not accurately quantified in the sample. Reported values were: 24.05 , 75.17, 3.285 and $11.47 \mu \mathrm{g} / \mathrm{ml}$ for AM, LF, AS 
and $\mathrm{AQ}$, respectively.

The lower limit of quantification (LOQ) is the smallest quantity of the targeted substance in the sample that can be assayed under experimental conditions with well defined accuracy. The definition can also be applicable to the upper limit of quantitation which is the highest quantity of the targeted substance in the sample that can be assayed under experimental conditions with well defined accuracy. The limits of quantitation were obtained by calculating the smallest and highest concentrations beyond which the accuracy limits or $\beta$-expectation limits go outside the acceptance limits. The dosing range is the interval between the lower and the upper limits where the procedure achieves adequate accuracy. Dosing ranges were 82.90 to $240 \mu \mathrm{g} / \mathrm{mL}$ for AM, 480 to $1440 \mu \mathrm{g} / \mathrm{mL}$ for $\mathrm{LF}, 80$ to $240 \mu \mathrm{g} / \mathrm{mL}$ for AS and 240 to $720 \mu \mathrm{g} / \mathrm{mL}$ for AQ, respectively.

The uncertainty is a parameter associated with the result of a measurement that characterizes the dispersion of the values that could reasonably be attributed to measurand. As shown in Table 6, relative expanded uncertainly (\%) have been found less than 7\%.

\subsection{Method Application}

The validated method was then used to determine the content of the four targeted compounds found in two sets of tablets samples with fixed dosage combinations. The first set consisted to five different brands coded A1, A2, A3, A4, A5, respectively, and claimed to contain artemether and lumefantrine while the second set coded B1, B2 was claimed to contain artesunate and amodiaquine. The results obtained for the analyses are presented in Table 7. They consisted in the mean percentage of claimed nominal content and the standard deviation computed on 3 independent samples. Specifications were set to $90.0 \%-110.0 \%$ of the claimed nominal content (mg). All the batches presented artemether and lumefantrine or artesunate and amodiaquine contents very close to the labeled amount and within the specifications. The artemether contents in the tablet samples were within $99.1 \%$ to $100.6 \%$, while those of lumefantrine within $94.6 \%$ to $99.9 \%$. The artesunate contents in the tablet samples were within $99.3 \%$ to $100.7 \%$ and those of amodiaquine within $93.4 \%$ to $104.4 \%$.

\section{Conclusion}

In the perspective of fighting against poor quality antimalarials, we undertake the development and validation of one generic procedure of dosage (HPLC-UV/Isocratic mode) for the simultaneous quantification of two WHO's recommended ACTs in anti-malarial fixed-dose combination (artemether-lumefantrine and artesunate-amodiaquine) tablets by using the DoE/DS optimization strategy. Three Analytical factors were selected for the experimental design namely: Flow rate of mobile phase $(\mathrm{F})$, column temperature $\left(\mathrm{T}^{\circ} \mathrm{C}\right)$ and proportion of methanol in the mobile phase (\%OM). The experiments showed that only the Flow rate of mobile phase (F) and proportion of methanol in the mobile phase (\%OM) had significant effects on peak separations within the explored experi-

Table 7. Content of seven samples marketed in DRC, Rwanda and Benin.

\begin{tabular}{|c|c|c|c|c|c|}
\hline \multirow{2}{*}{ Drug } & \multicolumn{2}{|c|}{ Artemether (AM)—Lumefantrine (LF) } & \multicolumn{2}{|c|}{ Artesunate(AS)—Amodiaquine (AM) } & \multirow{2}{*}{$\begin{array}{l}\text { Country o } \\
\text { Sampling }\end{array}$} \\
\hline & Artemether & Lumefantrine & Artesunate & Amodiaquine & \\
\hline A1 & $\begin{array}{c}20 \mathrm{mg} \\
100.6 \% \pm 1.8 \%\end{array}$ & $\begin{array}{c}120 \mathrm{mg} \\
99.9 \% \pm 0.6 \%\end{array}$ & - & - & Benin \\
\hline A2 & $\begin{array}{c}20 \mathrm{mg} \\
100.1 \% \pm 0.9 \%\end{array}$ & $\begin{array}{c}120 \mathrm{mg} \\
98.0 \% \pm 0.4 \%\end{array}$ & - & - & Benin \\
\hline A3 & $\begin{array}{c}20 \mathrm{mg} \\
100.2 \% \pm 1.2 \%\end{array}$ & $\begin{array}{c}120 \mathrm{mg} \\
98.2 \% \pm 0.8 \%\end{array}$ & - & - & Benin \\
\hline A4 & $\begin{array}{c}20 \mathrm{mg} \\
99.1 \% \pm 1.5 \%\end{array}$ & $\begin{array}{c}120 \mathrm{mg} \\
94.8 \% \pm 0.9 \%\end{array}$ & - & - & Rwanda \\
\hline A5 & $\begin{array}{c}80 \mathrm{mg} \\
100.5 \% \pm 0.5 \%\end{array}$ & $\begin{array}{c}480 \mathrm{mg} \\
94.6 \% \pm 0.3 \%\end{array}$ & - & - & DRC \\
\hline B2 & - & - & $\begin{array}{c}50 \mathrm{mg} \\
100.7 \% \pm 0.7 \%\end{array}$ & $\begin{array}{c}153 \mathrm{mg} \\
93.4 \% \pm 0.2 \%\end{array}$ & DRC \\
\hline B3 & - & - & $\begin{array}{c}100 \mathrm{mg} \\
99.3 \% \pm 0.3 \%\end{array}$ & $\begin{array}{c}270 \mathrm{mg} \\
104.4 \% \pm 0.5 \%\end{array}$ & DRC \\
\hline
\end{tabular}


mental domain. Design space strategy led to the development of one fast HPLC method able to screen 9 AAI and one for the simultaneous quantitation of two WHO's recommended ACTs in anti-malarial FDC (AM-LF and AS-AQ) tablets. The LC method developed for the simultaneous quantitation offers the advantage of being used in isocratic mode, unlike the methods of the American and international pharmacopoeias offering the gradient mode and are time consuming. This method was then successfully validated prior to selectivity, linearity, accuracy, trueness and precision, for simultaneous quantitation of AM, LF, AS and AQ using the approach based on total error and accuracy profile as decision tool. This method can be applied in the routine regulatory quality control of $\beta$-artemether and lumefantrine, artesunate and amodiaquine containing FDC drug products. Application to 7 commercial antimalarial formulations marketed in Benin (West Africa), DRC (Central Africa) Rwanda (East Africa) and containing AM/LF or AS/AQ per tablet gave a content in good agreement with the declared content. This study was the first report of simultaneous determination of artemether lumefantrine artesunate and amodiaquine in fixed dose combination tablets.

\section{Acknowledgements}

Many thanks are due to the "ARES-CCD (Académie de Recherche et d'Enseignement supérieur-Commission de la Coopération au Développement) or previous Commission Universitaire pour le Développement” of Belgium for fellowship grant of Jérémie Mbinze Kindenge. The authors would like to thank Fourrts laboratories (Chennai, India) and Meridian Pharmacare Pvt Ltd. (Bangalore; Inde) for the provision of the reference substances and the excipients.

\section{References}

[1] World Health Organization (2013) World Malaria Report 2013. WHO Press, Geneva.

[2] Malaria Consortium (2014) Artemisinin-Based Combination Therapy. http://www.malariaconsortium.org

[3] World Health Organization (2014) Substandard and Counterfeit Medicines. http://www.who.int/mediacentre/factsheets/2003/fs275/en/

[4] Newton, P.N., Dondorp, A., Green, M., Mayxay, M. and White, N.J. (2003) Counterfeit Artesunate Antimalarials in Southeast Asia. Lancet, 362, 169. http://dx.doi.org/10.1016/S0140-6736(03)13872-X

[5] Mbinze, J.K., Dispas, A., Lebrun, P., Mavar Tayey Mbay, J., Habyalimana, V., Kalenda, N., Rozet, E., Hubert, P. and Marini, R.D. (2013) Application of an Innovative Design Space Optimization Strategy to the Development of LC Methods for the Simultaneous Screening of Antibiotics to Combat Poor Quality Medicines. Journal of Pharmaceutical and Biomedical Analysis, 85, 83-92. http://dx.doi.org/10.1016/j.jpba.2013.06.036

[6] Mbinze, J.K., Lebrun, P., Debrus, B., Dispas, A., Kalenda, N., Mavar Tayey Mbay, J., Schofield, T., Boulanger, B., Rozet, E., Hubert, Ph. and Marini, R.D. (2012) Application of Aninnovative Design Space Optimization Strategy to the Development of Liquid Chromatographic Methods to Combat Potentially Counterfeit Nonsteroidal Anti-Inflammatory Drugs. Journal of Chromatography A, 1263, 113-124. http://dx.doi.org/10.1016/j.chroma.2012.09.038

[7] Habyalimana, V., Kalenda Tshilombo, N., Dispas, A., Mbinze, J.K., Kadima Ntokamunda, J.L., Lebrun, P., Hubert, P. and Marini Djang'eing'a, R. (2014) Méthodes chromatographiques génériques de criblage pour lutter contre les médicaments de qualité inférieure. Spectra Analyse, 298, 30-36.

[8] Debrus, B., Lebrun, P., Kindenge, J.M., Lecomte, F., Ceccato, A., Caliaro, G., Mbay, J.M., Boulanger, B., Marini, R.D., Rozet, E. and Hubert, Ph. (2011) Innovative High-Performance Liquid Chromatography Method Development for the Screening of 19 Antimalarial Drugs Based on a Generic Approach, Using Design of Experiments, Independent Component Analysis and Design Space. Journal of Chromatography A, 1218, 5205-5215. http://dx.doi.org/10.1016/j.chroma.2011.05.102

[9] International Conference on Harmonization (ICH) of Technical Requirements for Registration of Pharmaceuticals for Human Use, Topic Q8 (R2) (2009) Pharmaceutical Development. Geneva.

[10] Lebrun, P., Govaerts, B., Debrus, B., Ceccato, A., Caliaro, G., Hubert, Ph. and Boulanger, B. (2008) Development of a New Predictive Modeling Technique to Find with Confidence Equivalence Zone and Design Space of Chromatographic Analytical Methods. Chemometrics and Intelligent Laboratory Systems, 91, 4-16. http://dx.doi.org/10.1016/j.chemolab.2007.05.010

[11] Dewé, W., Marini, R.D., Chiap, P., Hubert, P., Crommen, J. and Boulanger, B. (2004) Development of Response Models for Optimising HPLC Method. Chemometrics and Intelligent Laboratory Systems, 74, 263-268. http://dx.doi.org/10.1016/j.chemolab.2004.04.016

[12] Debrus, B., Lebrun, P., Ceccato, A., Caliaro, G., Rozet, E., Nistor, I., Oprean, R., Rupérez, F.J., Barbas, C., Boulanger 
B. and Hubert, P. (2011) Application of New Methodologies Based on Design of Experiments, Independent Component Analysis and Design Space for Robust Optimization in Liquid Chromatography. Analytica Chimica Acta, 691, $33-$ 42. http://dx.doi.org/10.1016/j.aca.2011.02.035

[13] Memvanga, P.B., Mbinze, J.K., Rozet, E., Hubert, P., Préat, V. and Marini, R.D. (2014) Development of a Liquid Chromatographic Method for the Simultaneous Quantification of Curcumin, $\beta$-Arteether, Tetrahydrocurcumin and Dihydroartemisinin. Application to Lipid-Based Formulations. Journal of Pharmaceutical and Biomedical Analysis, 88, 447-456. http://dx.doi.org/10.1016/j.jpba.2013.09.009

[14] US Pharmacopeia (2014) USP 37-NF 32. www.uspnf.com

[15] International Pharmacopoeia (2007) Working Document QAS/07.197/Rev.1.

[16] Guillarme, D., Nguyen, D., Rudaz, S. and Veuthey, J.L. (2007) Method Transfer for Fast Liquid Chromatography in Pharmaceutical Analysis: Application to Short Columns Packed with Small Particle. Part I: Isocratic Separation. European Journal of Pharmaceutics and Biopharmaceutics, 66, 475-482. http://dx.doi.org/10.1016/j.ejpb.2006.11.027

[17] Hubert, P., Nguyen-Huu, J.J., Boulanger, B., Chapuzet, E., Cohen, N., Compagnon, P.A., Dewé, W., Feinberg, M., Laurentie, M., Mercier, N., Muzard, G., Valat, L. and Rozet, E. (2007) Harmonization of Strategies for the Validation of Quantitative Analytical Procedures: A SFSTP Proposal-Part III. Journal of Pharmaceutical and Biomedical Analysis, 45, 82-96. http://dx.doi.org/10.1016/j.jpba.2007.06.032

[18] Hubert, P., Nguyen-Huu, J.J., Boulanger, B., Chapuzet, E., Cohen, N., Compagnon, P.A., Dewé, W., Feinberg, M., Laurentie, M., Mercier, N., Muzard, G., Valat, L. and Rozet, E. (2008) Harmonization of Strategies for the Validation of Quantitative Analytical Procedures: A SFSTP Proposal: Part IV. Examples of Application. Journal of Pharmaceutical and Biomedical Analysis, 48, 760-771. http://dx.doi.org/10.1016/j.jpba.2008.07.018

[19] Food and Drug Administration (1995) International Conference on Harmonization: Guideline on Validation of Analytical Procedures: Definitions and Terminology. Federal Register, 60, 11260-11262

[20] Hubert, P., Nguyen-Huu, J.J., Boulanger, B., Chapuzet, E., Chiap, P., Cohen, N., Compagnon, P.A., Dewe, W., Feinberg, M., Lallier, M., Laurentie, M., Mercier, N., Muzard, G., Nivet, C. and Valat, L. (2003) Validation des procédures analytiques quantitatives Harmonisation des démarches. STP Pharma Pratiques, 13, 101-138.

[21] Boulanger, B., Rozet, E., Moonen, F., Rudaz, S. and Hubert, P. (2009) A Risk-Based Analysis of the AAPS Conference Report on Quantitative Bioanalytical Methods Validation and Implementation. Journal of Chromatography B, 877, 2235-2243. http://dx.doi.org/10.1016/j.jchromb.2009.06.019

[22] The European Medicines Agency (1996) Note for Guidance on Manufacture of the Finished Dosage Form. www.ema.europa.eu/docs/en_GB/document_library/Scientific_guideline/2009/09/WC500002916.pdf 
Scientific Research Publishing (SCIRP) is one of the largest Open Access journal publishers. It is currently publishing more than 200 open access, online, peer-reviewed journals covering a wide range of academic disciplines. SCIRP serves the worldwide academic communities and contributes to the progress and application of science with its publication.

Other selected journals from SCIRP are listed as below. Submit your manuscript to us via either submit@scirp.org or Online Submission Portal.
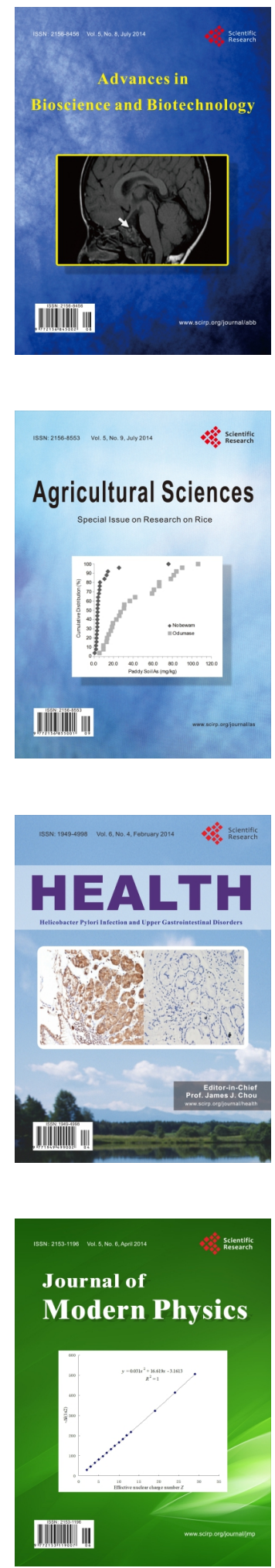
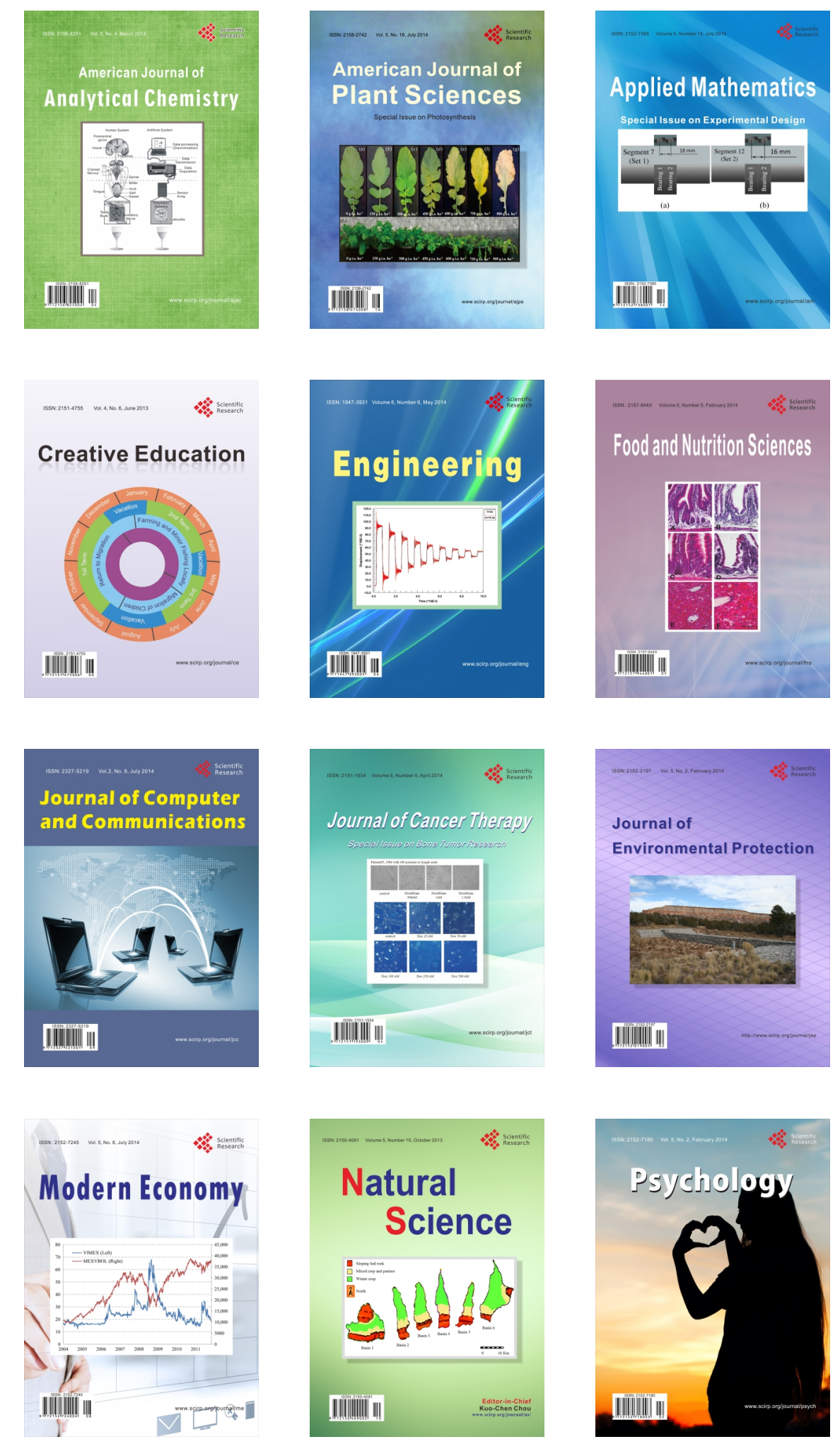